Editorial

\title{
Staging accuracy in colorectal cancer:A pathologic and therapeutic dilemma
}

\section{Editorial}

Colorectal cancer is one of the most prevalent and leading causes of cancer death worldwide. ${ }^{1}$ The survival of patients with potentially curable colorectal cancer is mainly determined by pathologic tumor and lymph node staging. In locoregional disease, the extent of lymph node involvement is the most significant indicator for disease freeand overall survival rates. ${ }^{2}$ Currently, the American Joint Committee on Cancer (AJCC) the tumor node metastasis (TNM) staging system is widely used for staging colorectal cancer. According to this staging system, lymph node staging is defined based on the number of involved lymph nodes. ${ }^{3}$ Evaluation of at least 12 lymph nodes is currently considered as an adequate node staging in colorectal cancer. ${ }^{4}$ However, despite advances in colorectal surgery, inadequate lymph nodes examination remains a common practice in resected colorectal cancer. ${ }^{5,6}$ This pitfall is more prominent in the rectal location, particularly in cases receiving neoadjuvant chemoradiation. ${ }^{5,7}$ In an analytical review, the mean total number of lymph nodes examined was 10.9 , while $5.4 \%$ of patients having no lymph node identified and only $41.2 \%$ of all patients had adequate $(\geq 12)$ lymph node evaluation. ${ }^{5}$ Insufficient lymph nodes staging of colorectal cancer can potentially lead to understaging of patients with stage III and categorizing these tumor as stage I and II disease. ${ }^{8}$ Subsequently, it causes a significant clinical challenge for predicting the prognosis and determining adjuvant treatments. ${ }^{2}$

In addition, many recent studies investigated the prognostic impact of total lymph node identified and ratio of lymph nodes in resected colorectal cancer. ${ }^{2,9}$ In another review, Ghahramani et al., ${ }^{10}$ found the higher number of assessed lymph nodes as a favorable prognostic factor for overall survival in 10 out of 11 studies on node negative colorectal cancer. Furthermore, in 14 out of 15 studies on node positive (stage III) colorectal cancer, higher lymph node ratio was a poor prognostic indicator for overall and/or disease free survival. The authors concluded that tumor stage might be a more useful prognostic indicator compared to node stage in the patients with inadequate lymph node staging. ${ }^{10}$

The exact mechanism by which inadequate lymph node evaluation leads to poor survival of patients with colorectal cancer remains to be defined; however, incomplete lymph node dissection and inaccurate lymph node staging are the most important factors. Therefore, optimizing surgical techniques and pathologic review of surgical specimen are suggested for improving the number of lymph node identified in patients with colorectal cancer.

\section{Acknowledgments}

None.

\section{Conflicts of interest}

Author declares there are no conflicts of interest.
Volume I Issue 4 - 2014

\author{
Mohammad Mohammadianpanah \\ Colorectal Research Center, Shiraz University of Medical \\ Sciences, Iran
}

Correspondence: Mohammad Mohammadianpanah, Colorectal Research Center, Shiraz University of Medical Sciences, 71936, Shiraz, IR Iran, Tel 98-7II6I25I68, Fax 987II6474320,

Emailmohpanah@gmail.com,mohpanah@sums.ac.ir

Received: November II, 2014 | Published: December 23, 2014

\section{References}

1. Jemal A, Bray F, Center MM, et al. Global cancer statistics. CA Cancer J Clin. 2011;61(2):69-90.

2. Chang GJ, Rodriguez-Bigas MA, Skibber JM, et al. Lymph node evaluation and survival after curative resection of colon cancer: systematic review. J Natl Cancer Inst. 2007;99(6):433-441.

3. Colon Rectum. AJCC Cancer Staging Manual. In: Edge SB et al. (Eds.), American Joint Committee on Cancer. $7^{\text {th }}$ ed. Springer: New York, USA; 2010. 143 p.

4. Shia J, Wang H, Nash GM, et al. Lymph node staging in colorectal cancer: revisiting the benchmark of at least 12 lymph nodes in R0 resection. J Am Coll Surg. 2012;214(3):348-355.

5. Ghahramani L, Razzaghi S, Mohammadianpanah M, et al. Adequacy of Lymph Node Staging in Colorectal Cancer: Analysis of 250 Patients and Analytical Literature Review. Ann Colorectal Res. 2013;1(1):3-11.

6. Baxter NN, Virnig DJ, Rothenberger DA, et al. Lymph node evaluation in colorectal cancer patients: a population-based study. J Natl Cancer Inst. 2005;97(3):219-225.

7. Omidvari S, Hamedi SH, Mohammadianpanah M, et al. Comparison of abdominoperineal resection and low anterior resection in lower and middle rectal cancer. J Egypt Natl Canc Inst. 2013;25(3):151-160.

8. Pheby DF, Levine DF, Pitcher RW, et al. Lymph node harvests directly influence the staging of colorectal cancer: evidence from a regional audit. J Clin Pathol. 2004;57(1):43-47.

9. Thomas M, Biswas S, Mohamed F, et al. Dukes C colorectal cancer: is the metastatic lymph node ratio important? Int $J$ Colorectal Dis. 2012;27(3):309-317.

10. Ghahramani L, Moaddabshoar L, Razzaghi S, et al. Prognostic Value of Total Lymph Node Identified and Ratio of Lymph Nodes in Resected Colorectal Cancer. Ann Colorectal Res. 2013;1(3):81-91. 